\title{
SOBRE LA (NO) CLAUSURA DE LA ARAUCANA ${ }^{1}$ \\ On the (non) closure de La Araucana
}

\section{Eduardo Barraza*}

\section{Resumen}

La reapertura del mundo textual de La araucana no se reduce a que sirva de modelo para la escritura de otros textos que refieren la guerra de Arauco sino a que inaugura una serie textual que incluye, también, el "juego al trocado” relativo a empresas españolas fracasadas — no dignas de canto o de memoria- así como el triunfo de los indígenas sobre los españoles. Se trata de una serie que promueve una reescritura y discusión del canon épico y de sus formantes irresueltos, que se prolonga intermitentemente en la literatura chilena. Tal situación puede ser examinada ventajosamente con una categoría analítica como es “el discurso de la conquista”.

Palabras clave: La araucana; reescritura; canon; discurso; conquista.

Abstract

The reaperture of the textual world of La araucana is not reduced to its service as a model to other texts which refer to the Arauco war but to the innauguration of a textual series that includes, also, the "juego de trocado" relative to the unsuccessful Spanish initiatives — not worthy of song or memory - but also the triumph of the indigenous people over the Spaniards. This series promotes a rewriting and discussion of the epic canon and of its unresolved formants, which is prolonged, intermittently, in Chilena literatura. Said situation can be examined advantageously with an analytic category such as "the conquest discourse".

Key words: La araucana; rewriting; canon; discourse; conquest.

"Será mejor que llore y que no cante" es el conocido verso con el cual Ercilla pone fin a La Araucana, acto de habla que - por el contrario- no logra evitar una "secuela", o una escritura hecha "al olor y rastro" de ella. Esta reapertura contradice la voluntad del poeta por clausurar todo discurso sobre la guerra de Arauco. Sin embargo - y, más allá de los rasgos temáticos e imitativos de los continuadores de La Araucana - resulta que el canon épico, tal como preconiza Ercilla, a la vez que se torna anti-épico o elegíaco, muestra en su reverso la derrota de capitanes y de gobernadores españoles y el triunfo de los toquis araucanos, de todo lo cual resultarán las relatos contratextuales o contradictorios que refieren esas "historias no dignas de memoria" ni mucho menos de escritura. Por lo mismo, la re-apertura del mundo textual de $L a$ Araucana no se reduce a que sirva de modelo para el Arauco domado de Oña, $L a$

${ }^{1}$ Proyecto Fondecyt № 1085317: “El discurso de la conquista: una serie textual autónoma de la literatura chilena”. 


\section{Eduardo Barraza}

Araucana de Santistevan, el Purén indómito de Arias de Saavedra o La guerra de Chile (de autor anónimo, a la fecha) siendo notorio que, especialmente los dos últimos textos, responden a una serie textual, a una reescritura y discusión del canon épico y de sus formantes irresueltos que se prolonga intermitentemente en la literatura chilena, situación que puede ser examinada actualmente con una categoría analítica que denomino "el discurso de la conquista".

1.- Pocos textos como La Araucana han despertado prácticamente la unanimidad de juicio de sus pares, sean ellos Cervantes, Lope de Vega, Voltaire, Andrés Bello, por citar algunos. A la vez, las nutridas lecturas críticas de La Araucana dan cuenta de ella como una productividad macro-textual, sea en lo estrictamente literario o en lo que concierne a su carácter historiográfico. ${ }^{2}$ Se funda, así, el canon de una escritura de la conquista en términos de celebrar la victoria de unos y la derrota de otros, vale decir, macro-relato de las proezas, las hazañas de "aquellos españoles esforzados que a la dura cerviz de Arauco no domada/ pusieron duro yugo por la espada” (I:6,7,8) en suma, se constituye_un corpus de historias dignas de memoria, de recuerdo, registradas como textos, como discursos de alta significación en la cultura y conservados en la memoria colectiva (Mignolo, 1982).

"Nuestra admiración por la obra de Ercilla es tan grande que deseáramos que no hubiese en ella una sola siquiera de sus afirmaciones que contradijera la verdad”, dice José Toribio Medina cuando entra a considerar eufemísticamente "al poeta como hombre de negocios” y no “como prestamista” (1948:169), aduciendo que quienes recurrían a Ercilla lo hacían porque tales acciones correspondían a simples "contratos de mero comercio" (176-179) solicitados por quienes "en su leche habían bebido el culto a las monedas de oro" (170).

¿Qué verdades o afirmaciones podría contradecir la obra de Ercilla? ¿La de un enunciador que promete no cantar el amor? ¿La de hacer entera y acreditada relación historiográfica, avalada por su calidad de "testigo de vista" que, además, se ha "criado” en la Casa Real de Felipe II? ¿La de un soldado que es más poeta que cronista y que escribe sobre de la guerra de Arauco respondiendo a las exigencias de un género?

Recientemente, José Promis ha hecho un exhaustivo estudio respecto al proceso de la "formación literaria de la figura de Caupolicán”, advirtiendo que desde un punto de vista filosófico La Araucana se presenta como "un objeto que encierra una verdad falsa pero irrefutable”... constituyendo un ejemplo privilegiado de "palimpsesto" " de un tipo de texto que conserva perceptibles huellas de sucesivas escrituras (2009:197).

Por lo pronto, observemos que desde los umbrales textuales y extratextuales, la voz de Ercilla valida la paternidad de su escritura, la índole de

\footnotetext{
${ }^{2}$ La copiosa bibliografía sobre La Araucana — como la que consigna la Biblioteca Cervantesmuestra la diversidad de perspectivas, análisis y valoraciones de este texto de Ercilla.
} 
la misma en tanto "relación sin corromper/ cortada a medida de la verdad", (I:19) tanto como la correcta — cuando no la única — interpretación que permite a sus lectores, así como la serie de inclusiones que privilegia en su canto: "pongo justamente sólo aquello/ en que todos concuerdan y confieren,/ y en lo que en general menos difieren” (XII:550-552).

Por esta vía, más que pactar con su lector, Ercilla lo limita (u obliga) a un acuerdo de lectura unívoca, presuntamente transparente, no ambigua, sino irrebatible como aquella según la cual "esta obra se hizo en los mismos pasos y sitios de la guerra” (15) haciendo olvidar al lector que La Araucana ocupó más de treinta años de la vida de su autor. Conforme a un a cuantiosa bibliografía existente sobre $\mathrm{La}$ araucana, ¿Cuánta lectura crítica no se ha hecho a partir de esta "ley” de Ercilla? y ¿Cuánta otra no se ha hecho conforme a cada una de las justificaciones e interpretaciones que prescribe en los prólogos a las sucesivas partes de La Araucana.

Proponemos que la solidez de La Araucana radica en la reciedumbre del sujeto de la enunciación, en la remisión al yo que asume el canto sobre la guerra de Arauco como producto de su hacer, de su conocimiento de las exigencias retóricas de un género, más que de su testimonio. Ercilla maneja el curso, el ritmo, de su discurso y desde tal perspectiva determina — en primera instancia - el sentido de la guerra de Arauco como producto de la decisión de la Divina Providencia más que derivada del descubrimiento del "ignorante engaño" en que habrían incurrido los indígenas. El suspenso en que deja al lector en muchos de sus cantos obedece a su autoridad respecto al curso de su enunciación antes que al curso de la guerra; lo mismo, su decisión de inaugurar cada canto con digresiones ético-filosóficas antes que estrictamente bélicas (Goic, 1970;1971). En la clausura textual, el poeta es un "yo" que examina el curso de su vida y, particularmente, ante lo infructuoso, de su quehacer — por cuanto ha sido "poco 'el fruto' que ha sacado" con su oficio de escribir — decide "parar su pluma” (XXXVI:580-605). (Del mismo modo, en la promesa de "no cantar al amor" se afirma una referencia a una práctica literaria -la de Ariosto- antes que historiográfica, en la cual no se percibe su carácter restrictivo, hecho que discute T. Harris en Cipango (1992). "No las damas, amor, nos dijeron”). Esta reciedumbre del sujeto de la enunciación — comparable al uso del yo autobiográfico de Bernal Díaz- le permite construir una especie de blindaje en torno a su discurso contra el cual se estrellan objeciones literarias (como aquellas relativas a la unidad del poema, a la ausencia o presencia de un protagonista o su percepción de la naturaleza de Chile) u otras de carácter historiográfico como las que formula Góngora y Marmolejo en 1572

"Don Alonso de Arcila, caballero que en este reino estuvo poco tiempo en compañía de don García de Mendoza, escribió algunas cosas acaecidas en su Araucana, intitulando su obra con el nombre de la provincia de Arauco; y por no ser tan copiosa cuanto fuera necesario para tener noticia de todo cuanto del reino aunque por su buen estilo" (1960:77). 


\section{Eduardo Barraza}

Este "buen estilo" de La Araucana radicaría en que nos propone una dimensión posible del Nuevo Mundo mediante un proceso de de-semantización y de re-semantización del discurso que se impone a las declaradas pretensiones historiográficas. Se provoca, así, una suerte de "contradicción entre el nivel del decir y los actos que lleva consigo ese decir", de manera tal que la "verdad" de las afirmaciones y predicaciones que haga Ercilla sobre las vicisitudes de la guerra de Arauco, terminarán siendo comprobadas por la índole atributiva de la enunciación antes que por los eventos mismos o por las cualidades o por las acciones de los personajes. ${ }^{3}$ Pedro de Oña tiene muy presente esta condición del estilo de Ercilla cuando asume el riesgoso encargo de escribir sobre el protagonismo de García Hurtado de Mendoza en Arauco. Por lo mismo, la re-escritura de La Araucana, la transgresión, el no acatamiento a la demanda de Ercilla a que no se "cante" la guerra de Arauco deriva de advertir un silenciamiento, lo no dicho en ella por su condición de relación "no copiosa", a la intuición de que deja "algo escondido", oculto, pero, también, a que se produce un punto de oscuridad, un punto ciego o de caos en la pretendida claridad auto-exegética que proclama Ercilla (Promis, 2009; Triviños, 2001;2003). Igualmente, a que persiste su ineludible correlato historiográfico, pues la guerra de conquista de Arauco continúa a lo largo del siglo XVI y siguientes y tiene un curso y unos protagonistas dispares que no reproducen el ímpetu de los sucesos ocurridos durante las gobernaciones de Valdivia o de García Hurtado.

Por lo pronto, piénsese que Ercilla se limita a "cantar" los hechos de Arauco sucedidos hasta 1558 y sólo en 1589 hace pública su disputa con García Hurtado, el "acelerado juez" o "mozo acelerado", ocurrida 30 años antes, agravio que recuerda en los siguientes términos:

"aunque así agraviado, no por eso/ (armado de paciencia y duro hierro) falté en alguna ocasión y correría/ sirviendo en la frontera noche y día" (XXXVI:265-272).

Sin embargo,

“aceleré mi súbita partida; / que el agravio, más fresco cada día,/ me estimulaba siempre y me roía" (XXXVI:286-288) "Salí de aquella tierra y reino ingrato/ que tanto afán y sangre me costaba” (XXXVI:291-292).

Muerto en 1594, Ercilla no podrá discutir a Pedro de Oña quien, en 1596, re-configura y sostiene una tesis contraria respecto al curso de la guerra de

\footnotetext{
3 “La denuncia de Ercilla pasa por una elaboración literaria, ese filtro cortesano y letrado que le permite la alusión tangencial y oblicua, tanto como la figura ambivalente de un yo testigo que se desplaza en la yuxtaposición de lo heroico y lo antiheroico, de la sangre derramada de bárbara manera y el sentimiento de compasión y piedad. Como parte integrante del nosotros colectivo del ejército español empeñado en la invasión y el cruel despojo, él actúa en esa praxis contribuyendo a los excesos de la guerra injusta. Sin embargo, a la vez y en la posición de un Yo, se aleja de ese nosotros para escuchar y prestar ayuda a la mujer indígena” (Guerra, 2010:17).
} 
Arauco del mismo periodo, disputándole no necesariamente el estilo sino el silenciamiento de la excepcionalidad de García Hurtado, resquicio temático y contratextual que ha sido ampliamente estudiado por Mario Rodríguez (1981). Escritor por encargo, y aunque afirme que imita siguiendo el "olor y rastro de La Araucana”, Oña no advierte el carácter complejo y macrotextual de ella y los significados que propone o que se generan en su espacio textual. Por lo mismo, la declaración de "escribir siguiendo el rastro de Ercilla" resulta insuficiente y enmascarante, pues su énfasis radica en "construir un Arauco que termine siendo domado por García Hurtado de Mendoza, gobernador, soldado y cristiano ejemplar".

En 1597, Diego de Santistevan asume una tarea historiográfica y textual, por cuanto, si bien ha cesado el "canto" de Ercilla, la guerra prosigue inclaudicable y Arauco no ha sido domado como pretendía Oña, sino que como es de público conocimiento - dice- persiste "la obstinación de tan robustos y animosos bárbaros” (...). El propósito de Santistevan — declarado en la portada - no es "competir con" La Araucana ${ }^{4}$ sino "proseguir" y "acabar la historia de D. Alonso de Ercilla” quien en el canto XXXVI había dejado pendiente el proceso de la elección de un sucesor de Caupolicán

"Volveré a la consulta comenzada
De aquellos capitanes señalados
Que en la parte que dije disputada
Estaban diferentes y encontrados;
Contaré la elección tan porfiada,
Y cómo al fin quedaron conformados;
Los asaltos, encuentros y batallas,
Que es menester lugar para contallas” (337-345).

Esta es "la puerta abierta" que descubre Santistevan en el texto de Ercilla. Sólo que cruzar el umbral de La Araucana no se reduce a un recuento historiográfico de la guerra de Arauco, ni a disputarle el verosímil que ha impuesto el poeta épico. No obstante, Santistevan re-escribe la discutida "prueba del tronco" — empleada por Ercilla para la elección de Caupolicán como toqui- trocándola por una civilizada y "cabal elección" hecha ante un tribunal "en una caja de ébano labrada/ de unas menudas perlas guarnecida" (IV:II:5), proceso que — en una "segunda vuelta”- dará mayoría de votos a un hijo de Caupolicán, portador del mismo nombre de su padre, pero que no podrá reeditar su liderazgo. Obtendrá triunfos pero no tantos que le permitan vencer a los conquistadores y en un paso forzado entre la historia y la ficción —que tiende a degradación de la imagen bélica del toqui- optará por el suicidio,

4 “...No fue mi pensamiento/usurparle la fama que ha ganado/ sino acabar el punto de su historia/siendo suyo el laurel/suya la gloria”, expresa Santistevan en el canto VI. 


\section{Eduardo Barraza}

hecho que permitirá que sean "vencidas las indómitas Naciones, Antárticas, y bárbaras Regiones” (V:XX:167).

Santistevan no puede predecir que, al año siguiente, el desastre de Curalava demostrará que "la cerviz de Aruco no ha sido domada ni puesta al yugo por la espada”. La victoria de Pelantaro y de Anganamón sobre el gobernador García Oñez de Loyola y la posterior destrucción de las ciudades españolas fundadas en el sur, marcan un antes y un después del decurso de la guerra de Arauco. En el siglo XVII, la serie épica de la conquista dará cuenta de ese revés que se ha producido entre las fuerzas en pugna, tanto como en la sociedad de ese periodo, hechos de los cuales dan testimonio, también, los gobernadores y vecinos de Chile en su correspondencia cotidiana a sus familias o a la administración colonial (Barraza, 2006a;2006b;2007).

El "quebrantamiento" de las fuerzas españolas genera no sólo el discanto, la elegía, sino también una serie de historias no contadas sobre la guerra de Arauco. Tales discursos dan cuenta de los araucanos y de los purenes como vencedores $\mathrm{y}$, por lo mismo, “dignos de ser por graves preferidos”, según el programa narrativo de La guerra de Chile (I:2). En la guerra de Arauco se ha producido "el juego al trocado". Conforme a tal motivo, y contrariamente a las pretensiones de un "Arauco domado” por los españoles - como pretendían Oña y Santistevan $(1596,1597)$ — la guerra será objeto de un canto no necesariamente épico. Por lo pronto, observemos que el Purén indómito de Luis Arias de Saavedra (1610?) se inicia precisamente con el llanto, con un discurso elegíaco que provoca la muerte del gobernador Oñez de Loyola, precedida por variados “presagios celestes” (I:139).

Por lo mismo, el Purén indómito y La guerra de Chile (anónimo, h.1610) actúan transgresivamente como discursos contratextuales que se apartan del canon, pues, refieren sucesivas victorias de los purenes a partir del año 1598. Tales textos - al conceder protagonismo a "los rebeldes indios invencidos"discuten el canon épico de La Araucana y dan cabida a una serie de "historias no contadas" sobre la conquista. En consecuencia, no se sitúan en el polo de la percepción feliz de la guerra, pues ésta, en el curso del siglo XVII termina siendo calificada como una contienda "larga", "dilatada”, "envejecida", "grave”, "prolija” y "pesada”. En suma, la guerra de Arauco — como asegura el autor anónimo de La guerra de Chile - es un mal, una dolencia para la cual se debe contar con una adecuada medicina que debería ser aportada por los buenos gobernadores, pues los alzamientos indígenas "a un reino poderoso y rico tanto/ le tiene la cerviz ya quebrantada" (I:1).

Ambos textos se refieren mediante imágenes y símbolos semejantes a casos y sucesos ocurridos en Arauco y participan de una percepción similar de la guerra y de un modo de realización del discurso de la conquista que ha sido descrito como el de la "clausura de la epopeya de Arauco" (Triviños y 
Rodríguez, 1996) debido a la "dificultad para transformar la guerra en mito" (Rodríguez 1984). Tales juicios derivan, precisamente, de considerar la guerra de conquista únicamente como fuente y materia de mito; como discurso de memorables hazañas que originan exclusivamente el canto épico; como espectáculo auspicioso, percibido felizmente desde el bando español que sólo sabría de victorias en Arauco.

El caso es que la dilación de la "dura” guerra de Chile — términos con los cuales se refieren a ella cronistas, gobernadores y vecinos- concluye por vituperar al conquistador y por dignificar al rebelde que "de flaco será fiero y atrevido", como lo califica La guerra de Chile (III:205). Las incesantes rebeliones no sólo "dilatan” y prolongan la guerra sino que, al mismo tiempo, la hacen "grave", "pesada" y la "envejecen”, según plantean los autores de ambos poemas (1996: o. 1; 1984: o. 443, 696). Tal "envejecimiento" es percibido —en estos textos - con la imagen de una "desprolijidad" o in-sanidad que afecta a toda guerra de opresión que corrompe a todo ser viviente. La sociedad conquistadora aparece afectada por la guerra que actúa como una "voraz polilla” (Triviños, 1994) por todo lo cual se requiere de una cura o de un médico competente como podrían ser los gobernadores del periodo. Para Arias de Saavedra, Francisco de Quiñones — sucesor de Oñez de Loyola (entre 1599 y 1600) - deviene en el portador del antídoto que requieren los males del reino
"Conociendo Quiñones la dolencia que a todo el reino iba inficionando, fue con severidad y gran prudencia salutífero antídoto aplicando;
así la contagiosa pestilencia con aqueste remedio fue aplacando, que, como viejo médico y tan sabio, a cada cual curó del mal resabio” (XX:1603) ${ }^{5}$

La enfermedad que provoca la guerra degrada al cuerpo social, lo cubre de postemas (1996: oo. 224-225), al extremo que emana pestilencias (1984: XX:1603) y lo deja sin capacidad alguna de regeneración, de recuperación o de volver a ser quien era, quedando la guerra a merced de la destrucción, como aquél que provoca el "orín que corroe sus armas”, como se dirá en La guerra de Chile (XII:901).

\footnotetext{
${ }^{5}$ La memoria histórica desmiente la memoria poética que Arias hace del anciano gobernador (oo. 1603;1610-1611;1615). El epistolario de la época y las cartas del propio Quiñones contradicen este proceso metaficcional que ocurre en el poema. Su breve gobernación ha sido calificada por los historiadores como "la más deslucida y desgraciada." Quiñones padece los achaques propios de su vejez avanzada, al extremo que terminará su gobierno postrado, a raíz de lo cual escribe al Rey solicitándole lo releve del cargo por las dolencias que padece, aduciendo que es incapaz de permanecer al frente de la gobernación (Ferreccio, 1996:73).
} 


\section{Eduardo Barraza}

En consecuencia, la percepción de la guerra como degradación posibilita que surjan discursos que polemizan con ella, que no la magnifican sino que muestran su reverso, la heterogeneidad y disparidad de valores éticos, religiosos y políticos que en ella convergen, lo cual no es negado por el Purén indómito, pues, el poeta declara que para toda circunstancia tiene "encordado el instrumento" con que canta (III:158). Esta actitud permeable frente a la relación de la guerra de Arauco da paso al dis-canto, a una reacción de la escritura de la conquista que — sometida al canon de la preceptiva épica - contribuía a consumar la invención de Chile, hasta entonces valorada conforme al precepto de las memorables y dignas hazañas de españoles en América. Por lo mismo, las dificultades de la escritura en el Purén indómito y en La guerra de Chile no limitan únicamente con la imposibilidad de "transformar la guerra en mito" (Rodríguez, 1984). Sus autores, al tiempo que clausuran una faz preconizada de la guerra, dan paso a la apertura de un vasto espacio, silenciado e ilimitado, para el canto de otros hechos no necesariamente hazañosos. Por esta vía, ambos textos dan cuenta de las alteraciones producidas en la correlación de fuerzas enfrentadas en el curso de la dilatada guerra de Arauco. También, de los cambios operados en el discurso que hace referencia a ella, donde - a la par de hechos memorables, como los conoció, intuyó y ficcionalizó Ercilla- se han producido acciones transgresivas y escandalosas, "casos que jamás fueron contados" ni "cantados”, pero — según el horizonte narrativo de La guerra de Chile - por su gravedad son "dignos de ser” relevados del olvido de la historia y de la escritura (I:2).

Mostrar el lado oculto de la guerra de conquista es revelar su condición de ser una empresa destinada a la apropiación de territorios ajenos y a la privación de la libertad de los vencidos. Es referir, también, una serie de "bonicas y escandalosas hazañas" que —al hablar principalmente del fracaso, derrota, fuga, concupiscencia, violaciones o de la traición de españoles en Arauco - es el signo de la emergencia de una escritura disidente, refractaria al prestigioso paradigma literario vigente en el siglo XVI, que Gilberto Triviños describiera en los siguientes términos:

"Las numerosas historias que podemos denominar bonicas hazañas, con Pedro Mariño de Lobera y Bartolomé de Escobar, o bárbaros casos, con Alonso de Ercilla, forman el grupo de unidades narrativas que desenmascaran en Chile el reverso antiheroico de la empresa que las narraciones mitificadoras transfiguran en el tiempo de heroicos hechos y singulares hazañas de valerosos héroes (Vivar, Oña), comienzo glorioso del mayor bien que los indios deben a España (González de Nájera; Ovalle)” (1994:42-43).

Por el contrario, Ercilla soslaya cualquier posibilidad de una versión "escandalosa” de la guerra, que puedan constituir agravios, por ejemplo. Para satisfacción de su conciencia, no presenció el "bárbaro caso” que representó el 
suplico de Caupolicán. ${ }^{6}$ Menos concede espacio a los trabajos del "hambre” que enaltecía Pedro de Valdivia. A lo más confiesa
"Dejo de lado, por no cansaros y ser míos
Los inmensos trabajos padecidos,
La sed, hambre, calores y los fríos
La falta irremediable de vestidos;
Los montes que pasé, los grandes ríos,
Los yermos despoblados no rompidos,
Riesgos, peligros, trances y fortunas
Que aun son para contadas, importunas” (XXXVII:545-228).

Sin embargo, Arias de Saavedra en su Purén indómito, no estima que vaya a "importunar" a sus lectores con la inclusión de "escandalosas historias" de españoles aliados con los indígenas, como son las de Jerónimo Bello y, en especial, la de Juan Barba que se extiende entre los cantos XX y XXI, las que han sido mencionadas tangencialmente por cronistas e historiadores, por cuanto la mención de Barba es indicio no sólo historiográfico sino una pública denuncia y censura a la sociedad colonial escandalizada por la transgresión de los estamentos civiles, militares y religiosos que representa este personaje.

En el Purén indómito, Barba atestigua el tipo de "hombres descomulgados, perversos y mentirosos” (Triviños 1994:155ss) protagonistas de "hazañas escandalosas", razón por la cual es impropio del programa épico del Purén indómito que, si lo incluye, es para efectos de moralizar con la máxima de "quien mal obra, mal acaba" (XXI:1634) y para dar cuenta del "no deber ser" en Arauco, según se propone en la apertura del canto XXI. Por lo mismo, la presencia de Barba desde ese canto y los siguientes del poema, está destinada a fijar textualmente - y para la memoria histórica y colectiva - los estigmas que permiten desplegar "lo imaginario específico de los hombres ávidos de violencia” (Triviños 1994:158; Labarca, 1994; Barraza, 2004).

La suma de epítetos descalificadores que —en el Purén indómito- Arias de Saavedra aplica a Barba lo denigran, irremediablemente, por cuanto es presentado como: "bárbaro, enemigo de sí mismo, de Dios y del rey. Comparable a cualquier bruto. Perverso, impúdico, libidinoso. Peor que el disoluto Sardanápalo. Hereje, apóstata, iconoclasta, idólatra, hechicero, traidor caudillo de los purenes, pues entre ellos encuentra a sus pares en perversión, ya que "un malo entre los malos es querido" (XXI:1637ss).

\footnotetext{
6 "Si bien al principio de La Araucana se observa la intención de caracterizar a los indígenas como bárbaros en un sentido clásico, muy pronto esa especificidad que sería sólo propia de ellos fluye hacia las huestes de los españoles. El pasar las mujeres por la espada, sin siquiera perdonar a las preñadas ("mas los golpes al vientre encaminaban / y aconteció salir por las heridas/las tiernas pernezuelas no nacidas” I:p. 128) pareciera ser, dentro del contexto total de La Araucana, sólo la inscripción de un índice de lo bárbaro para señalar que va a ser desplazado, que va a cambiar de lugar para tener como referente a los propios españoles” (Guerra, 2010:19).
} 


\section{Eduardo Barraza}

Este retrato antiheroico de Juan Barba se constituirá, indudablemente, en texto y referencia obligada para el discurso historiográfico de cronistas y contemporáneos de Barba, como González de Nájera (1614) y Diego de Rosales (1666) quienes reiteran y legitiman en sus respectivos textos la condición dada a estos miserables fugitivos y traidores gestados en la guerra de Arauco. ${ }^{7}$

Por lo mismo, la atribución indebida del Purén indómito a Fernando Álvarez de Toledo (Ferreccio 1986:34-49) o el silenciamiento del nombre del autor de La guerra de Chile, tanto como la mutilación parcial de ambos textos pueden ser, entonces, considerados como la reacción de una institucionalidad literaria proclive a un paradigma estandarizado, reacio a dar cabida y a perpetuar la escritura de unos hechos y el nombre de unos autores que contradigan la conquista como empresa del ideal épico, y victoriosa siempre.

En consecuencia, que en La guerra de Chile se cante los efectos de una cruenta guerra que "tiene la cerviz quebrantada" del "poderoso" y "rico" reino de Chile es un vuelco radical de la serie épica de la conquista inaugurada por Ercilla, de modo tal que este poema — desde el anonimato en que permaneceactúa no sólo como imitación o secuela de La Araucana, sino más bien, como su contra-relato, como historia de la rebelión triunfante de los purenes —"no domados” como pretendía Pedro de Oña- encabezados por Pelantaro y Anganamón desde 1598. Esta condición de derrota y de "quebrantamiento" de los conquistadores no es advertida en las notas al pie de página de los editores de La guerra de Chile quienes se remiten sólo a establecer la semántica de los términos "reino" y "Estado" en los versos de la primera octava (I:95). Por lo mismo, ejes del discurso y dignos de canto para el poeta son ahora los victoriosos indígenas que se "han hecho memorables por la espada" sustentando el valor de Arauco (I:1). Tal es el inédito e incómodo proyecto contra-escritural que desarrolla y enfatiza La guerra de Chile. No se trata simplemente de un dejarse llevar por "el rastro y el olor de La araucana", sino de un relato cuyos protagonistas son unos indígenas rebeldes, héroes dignos — pero del otro bando- que no perduraron en sus victorias o que no fueron víctimas de una muerte heroica —o a traición — como la sufrieron Lautaro y Caupolicán, ni que menos se suicidaron bárbaramente. Como lo proclama en el canto VIII de $L a$ guerra de Chile un "fugitivo-náufrago-peregrino" y famélico español que busca socorro entre sus pares, este discurso disidente pretende que los españoles "sepan bien", de las virtudes del indígena vencedor, de "los hechos y el valor de ánimo ardiente” de indómitos y “rebeldes indios invencidos” (VIII:561).

\footnotetext{
${ }^{7}$ Vale decir, desde el discurso del Purén indómito se avala la legitimidad que asiste a los españoles para perseguir a los mapuches e "indios blancos" como herejes, reacios a la fe y a las paces pactadas, todo lo cual legitima la esclavitud o el aniquilamiento de los vencidos. Tal es la tesis que discute Eduardo Labarca en Butamalón (1994).
} 
En tal sentido, el Purén indómito y La guerra de Chile extienden ahora el favor de Marte hacia el mundo araucano, de modo tal que en el "contumaz bárbaro alevoso” /...”s'encierra / el furibundo Marte sanguinoso” (III:157-158). Pelantaro y Anganamón actúan como agentes del canto de una victoriosa guerra de restauración tendiente a recuperar sus límites territoriales y a "sustentar" su libertad. Por el contrario, el bando español padece un caos moral, civil y militar (XX:1602-1609) de autodestrucción que no pudo ser aplacado durante el breve gobierno del "virtuoso" Francisco de Quiñones, a quien en El Purén indómito se califica como

"gran legislador, Numa moderno,

Perseguidor mortal de la malicia

Asombro de las Furias del infierno

abismador de la cruel cobdicia" (XX:1615).

Según Arias de Saavedra, Quiñones encuentra en Chile un verdadero mundo al revés donde

"Menos valía el noble que el villano,
gobernaba el cobarde al animoso
al con ojos, el ciego, el cojo al sano
el fácil al constante valeroso
el soberbio al humilde, el mozo al cano
el sin piedad alguna al piadoso,
el ignorante al sabio, el loco al cuerdo
al despierto el dormido y sin acuerdo" (XX:1607).

El desarrollo alcanzado en Chile a fines del siglo XVI parece confirmar la alabanza de la tierra efectuada por Valdivia: Chile es un territorio donde un conquistador puede forjarse una fortuna que podría ser mayor si no fuera por los gastos que demanda la guerra. Además, llegar a la vejez y no morir en la guerra - como preconizara Valdivia - es tanto o más laudable porque permite gozar del descanso y del fruto de lo que rentan los indios encomendados o el comercio. Tal prosperidad no es valorada positivamente por los textos épicos de este periodo. Hacia 1569, La Araucana moraliza respecto a que la riqueza termina por superar el imperio de la justicia, por cuanto denuncia que en tiempos de Valdivia

"A costa del sudor y daño ajeno

la hambrienta y mísera codicia

Con libertad paciendo iba sin freno" (I:541-544).

Del mismo modo, en Arauco domado (1596), Oña afirma que a la llegada de García Hurtado de Mendoza, en Chile había

"Gran ocio, poco ejemplo, mucho vicio (los que)

Eran causa de excesos desiguales" (10) 


\section{Eduardo Barraza}

A su vez, el padre Alonso de Ovalle escribe que hacia 1597, cuando gobierna Martín García Oñez de Loyola,

"Las ciudades de la Imperial, Valdivia y Villarrica padecían, no ya calamidades ocasionadas de la guerra, sino otras más perjudiciales y perniciosas que traía consigo el ocio y prosperidad de que gozaban con la paz” (11).

Establecidos estos componentes de un mundo al revés, no propicio para el canto épico, los caciques rebelados pueden perfectamente criticar, por ejemplo, las premisas de la evangelización, como justificación de la conquista, como hace Pailamacho en el Purén indómito (III:167-193), al tiempo que Anganamón, en La guerra de Chile, sostiene que "el bautismo no da luz sino que ciega” (207). Por su parte, es el mismo Anganamón quien, en el Purén indómito, define el nuevo orden de la contienda como instancias propias de "un juego al trocado". Tal expresión hace referencia al cambio del curso de la guerra y al vuelco, trueque o "mudanza" de la fortuna a favor de Arauco, reflejo del tópico del mundo al revés pero entendido, ahora, como legítima vuelta a un natural orden indígena originario

"De señoras, viudas y doncellas

bien sé yo que es el número crecido

y qués justa razón servirnos dellas

como ellos de las nuestras se han servido;

podremos engendrar hijos de ellas

ya que las nuestras dellos han parido,

que pues que así las suertes se han mudado,

jugaremos con ellos al trocado" (X:773).

Conforme a esta fórmula del "juego al trocado", podemos concluir que - contrariamente a la clausura de todo canto sobre la guerra de Arauco que postula Ercilla - luego del levantamiento general de 1598, araucanos y purenes dejan de ser las víctimas y recuperan su calidad de señores de la tierra y de servidores — o esclavos del español — pasan a ser servidos. De este modo, frente a la pretensión de un "Arauco domado", según Oña, "la libertad se repara o se re-conquista" viene a ser la máxima con la cual se sintetizan los proyectos antitéticos que presiden la guerra de Arauco a partir de la rebelión de Pelantaro. Frente al alzamiento araucano, en Ercilla y Oña, el español busca re-cuperar, restaurar, re-fundar un orden, esa huella exógena de Occidente - civilizadora y fundadora - que ha impuesto en un mundo ajeno por medio de la conquista. Por el contrario, tanto en el Purén indómito como en La guerra de Chile, explicitan índole contratextual del conflkicto: la rebelión de los purenes, triunfante hasta entonces, busca que "la libertad esté en su puesto" (I:30), que se logre el retorno hacia un orden propio como augura el machi Pangalino en La guerra de Chile (III:208-214). En suma, se explicita que el objetivo de la rebelión mapuche es restaurar la tradición del "admapu" y la re-conquista de un territorio usurpado, empresa no 
ajena a las leyes de la guerra como las de la clemencia con el vencido que promete Anganamón a los defensores de La Imperial en el Purén indómito (XXI:16591676).

En tal sentido, frente a la serie textual que inaugura Ercilla, el triunfo araucano significa no sólo el "perdimiento del reino de Chile" para España y la percepción infausta y degradada de la guerra sino que, en especial, expresa que se ha producido la ruptura de la cohesión moral, civil y militar de la sociedad conquistadora que ha trocado la civilización en barbarie y que, incluso, en el canto IX del Purén indómito, sufre la mofa de Anganamón que huye de una prisión disfrazado de mujer, pues no cree que el oro dado a sus captores le garantice la libertad. Por lo mismo, en este poema, ninguno de los capitanes ni gobernadores de la época — sean ellos Oñez de Loyola o Quiñones- pueden restaurar o re-fundar el reino de Chile - como pudo hacerlo Eneas con respecto a Roma, luego de la destrucción de Troya (o. 1931) - como desea Arias de Saavedra que Quiñones lo sea (XXIV:1931).

Por el contrario, según La guerra de Chile, Anganamón, el toqui de los purenes - es presentado como el arquetipo del caudillo, el "espejo / en quien mirando todos el bien vemos” (III:230), todo lo cual se enfatiza en el Purén indómito cuando se sostiene que la destrucción de ciudades deriva de que los españoles son una sociedad conquistadora "de vicios llena y de virtud y justicia escasa” (o. 357) que sólo depende de la oración cristiana y, por lo mismo, está carente de héroes.

A su vez, según La guerra de Chile, por el espacio y el litoral de Arauco circulan ahora lamentablemente los españoles, "hechos de puro duelo un triste ejemplo” (X:786-788). No victoriosos sino vencidos; extraviados, náufragos, peregrinos, (oo. 379-388). Se trata ahora no de afamados sino de miserables y famélicos españoles como Pereda —entre los cantos II y III, o Andrés Pérez en los cantos XIX y XX del Purén indómito- que buscan salvar sus vidas ocultándose en ciénagas, grietas de la tierra, o troncos huecos de los árboles.

En suma, el "trocado de la guerra" que experimentan los españoles da origen a casos y sucesos lamentables y a "indignas y desesperadas hazañas”, "al mundo nuevas”. Entre ellas, "las impías fiestas” en la cuales los españoles dan muerte sin honor a indígenas mientras se hallan dormidos, según expresa La guerra de Chile (VI:463-472). Estos hechos son imposibles de ser mostrados — según se hacía en la antigua Roma - como tributos en el templo de la Honra (Idem,VIII: 623), con todo lo cual se constituye "aquesta desdichada y triste historia", como es calificada la que se narra en el Purén indómito (IV:260). Tales acciones y sucesos originan en La guerra de Chile no la alabanza sino el vituperio de la guerra, efectuada por los vencidos: ella es "cebo", "ponzoña”, “enfermedad de reinos pura”, "mísero apetito de la vida”, "monstruo voraz” (oo. 294-359-389-390-628). El eco de estas descalificaciones es la voz del poeta de La guerra de Chile que busca un Olimpo al 


\section{Eduardo Barraza}

modo de un "imperio ajeno de mudanza y pesadumbre (X:792-793), declarando con decepción que ha des-gastado "materialmente" su pluma en este pesaroso trabajo de la escritura de la guerra (II:165). Arauco le muestra reiteradamente lo elegíaco, ese reverso de la hazañosa Troya donde se percibe lo infausto y el dolor de la guerra y donde cada muerto es un libro, una lección para los sobrevivientes, (VI:444) y el soldado deviene en un "obrero de la muerte", en un actor en un escenario de drama, no de la fama sino de la pesadumbre.

En síntesis, la reapertura del mundo textual de La araucana no se reduce a "escribir al olor de ella o siguiendo su rastro" ni que sirva de modelo para la escritura de otros textos que refieren la guerra de Arauco sino a que inaugura una serie textual que incluye, también, el "juego al trocado" relativo a fracasadas empresas de la conquista —no dignas de canto o de memoria— así como el triunfo de los indígenas sobre los españoles. Se trata de una serie que promueve una reescritura y discusión del canon épico y de sus formantes irresueltos, que se prolonga intermitentemente en la literatura chilena. Tal situación puede ser examinada ventajosamente con una categoría analítica como es "el discurso de la conquista".

Universidad de Los Lagos* Departamento de Humanidades y Arte Avda. Alcalde Fuchslocher 1305. Osorno (Chile) e.barraza.j@hotmail.com 


\section{BIBLIOGRAFÍA}

Arias de Saavedra, Diego. Purén indómito. Prólogo y edición crítica de Mario Ferrecchio Podestá y Raisa Kordic. Estudio Preliminar de Mario Rodríguez. Santiago de Chile: Biblioteca Antigua Chilena, vol 4, 1986.

Barraza, Eduardo. 2004. De La Araucana a Butamalón. El discurso de la conquista y el canon de la literatura chilena. Valdivia. Anejos Filológicos $\mathrm{N}^{\circ} 17$, Universidad Austral, 2004.

------ 2006 a) “La cotidianeidad de la guerra de Arauco”. Baton Rouge: Lousiana State University.

------- 2006 b) “De vecinos y gobernadores en el Reino de Chile”. Arica. Universidad de Tarapacá. Actas Sociedad Chilena de Estudios Literarios (SOCHEL).

Bello, Andrés. "La Araucana, por don Alonso de Ercilla y Zúñiga”, en Obras Completas, Tomo IX. Caracas: La Casa de Bello, 1981:349-362.

Concha, Jaime. "El otro Nuevo Mundo”, en V.V.A.A. Homenaje a Ercilla. Universidad de Concepción, 1970:31-82.

Ercilla y Zúñiga, Alonso de. La Araucana. Santiago de Chile: Del Pacífico, 1980.

Goic, Cedomil. "Poética del exordio en La Araucana", en Revista Chilena de Literatura (1970):5-22.

------- "La tópica de la conclusión en Ercilla”, en Revista Chilena de Literatura, $\mathrm{N}^{\circ} 4$ (1971):17-34.

Góngora y Marmolejo, Alonso de. Historia de Chile desde su descubrimiento hasta el año 1575. Prólogo, selección y notas de Rolando Mellafe Salas. Santiago de Chile: Universitaria, 1960.

Guerra, Lucía. "De la historia y otras barbaries: La Araucana de Alonso de Ercilla y Zúñiga en el imaginario nacional de Chile”, en Anales de Literatura Chilena No 14 (Diciembre, 2010):13-32.

Harris, Tomás. Cipango. Santiago de Chile: Documentas-Cordillera, 1992.

Lagos, Ramona. "El incumplimiento de la programación épica en $\mathrm{La}$ Araucana”, en Cuadernos Americanos 238, 5. (1981):157-191.

Promis, José. "Formación de la figura de Caupolicán en los primeros cronistas del Reino de Chile”, en Rebeldes y aventureros: del Viejo al Nuevo Mundo. Cortés, Hugo R.; Godoy, Eduardo; Insúa Mariela (Editores). Universidad de Navarra//Iberoamericana-Vervuert, 2008:195-220.

Medina, José Toribio. Vida de Ercilla. México: F.C.E., 1948.

Mejías López, William. Las ideas de la guerra justa en Ercilla y La Araucana. Santiago de Chile: Universitaria, 1992.

Oña, Pedro de. Arauco domado. Santiago de Chile: Universitaria, 1981.

Ovalle, Alonso de. Histórica relación del Reino de Chile. Santiago, Chile: Pehuén Editores, 2003. 
Rodríguez, Mario. "Un caso de imaginación colonizada: Arauco domado de Pedro de Oña”, en Acta Literaria Nº6 (1981):79-92.

------- "Un juego de ajedrez mal entablado": las estrategias del poder en el Purén indómito", en Acta Literaria N²5, 2000.

San Juan, Gregorio. Alonso de Ercilla (Cuarto Centenario). Bilbao: Gestingraf, 1994.

Santistevan Osorio, Diego de. La Araucana. Cuarta y Quinta Parte en que se prosigue y acaba la historia de D. Alonso de Ercilla hasta la reducción del valle de Arauco, en el Reino de Chile. Madrid: Francisco Martínez Abad, Editor, 1735, $3^{\text {a }}$ Reimpresión.

Gilberto Triviños. La polilla de la guerra en el Reino de Chile. Santiago de Chile: La Noria, 1994.

------- "Revisitando la literatura chilena: "Sigue diciendo cayeron - di más: volverán mañana”, en Atenea N487, I Sem. (2003):113-133.

------- "La buena nueva”, en Guillermo Bravo Acevedo y Jorge Pinto Rodríguez (Editores). Chile, 1880-1930. Literatura e historia social. Santiago de Chile: Universidad Metropolitana de Ciencias de la Educación, 2001, 139-198.

------- “La sombra de los héroes”, en Atenea No 465 y 466 (1992):67-97.

Triviños, Gilberto y Rodríguez, Mario. "La clausura de la epopeya en La guerra de Chile”, en Estudios Filológicos №31 (1996):39-56. 